\title{
XIUHCÓATL TALLADA EN PIEDRA DEL MUSEUM OF MANKIND, LONDRES
}

\section{Por Nelly Gutiérrez Solana}

Las innumerables representaciones prehispánicas de serpientes son, en su mayoría, de una calidad estética extraordinaria. El profundo arraigo que tuvo en la mente indígena la imagen de los ofidios se reflejó en el papel fundamental que éstos desempeñaron dentro de su religión, y en el constante impulso que motivó al indio a plasmar la figura de estos reptiles, utilizando todo tipo de materiales y técnicas.

El notable ejemplar de la Xiuhcóatl aquí estudiado, me llamó poderosamente la atención por sus cualidades formales, las cuales analizo a continuación. Mi interés no se limitó al aspecto formal, y así, me propuse indagar los ątributos de este ser fantástico, lo que nos relatan las fuentes acerca de él, y, dentro de las limitaciones existentes, establecer cuál fue su origen.

La escultura a la que me refiero, estuvo por mucho tiempo depositada en el Museo Británico, pero actualmente forma parte de la colección del Museum of Mankind de la misma ciudad de Londres (figuras 1 y 2). En su publicación de 1902, Seler la identifica como una Xiuhcóatl. Burland, en su libro de 1948, la adjudica a la cultura mexica. La pieza, de piedra basáltica, mide $76 \mathrm{~cm}$ de altura. Su grado de conservación es excelente, presentando sólo fracturas en la mandíbula inferior y en la prolongación de la superior. Las características que presenta la obra, y que permiten identificarla como una Xiuhcóatl, no se definen hasta el Posclásico Tardio, por lo cual, aunque no es posible asegurar, sin lugar a dudas, su origen mexica, si debe pertenecer al último periodo inmediatamente anterior a la conquista.

La Xiuhcóatl en cuestión, difiere radicalmente de las otras serpien. tes de fuego talladas en redondo que se conservan; de ahí su especial interés. Para hacer resaltar su singularidad la comparo en seguida con tres Xiuhcóatls pertenecientes a la cultura mexica. 1 Las tres se encuentran enroscadas, disposición común de las víboras dentro de la escultura azteca (figuras 3 y 4). La concepción volumétrica de estas tres culebras es totalmente distinta de la del Museum of Mankind; las primeras conforman un volumen cerrado, mientras que la otra, por su eje ondulante y

1 Las dos Xiuhcóatls, aquí ilustradas, pertenecen al Museo Nacional de Antropologia de México, la otra se exhibe en la colección Robert Wood Bliss, de Washington, D. C. 
por las concavidades que presenta, se integra estupendamente al espacio circundante.

El tipo de superficies limitantes de sus volúmenes es también radicalmente distinto. En el ejemplar aquí estudiado, dos superficies rectas se unen formando una arista viva, lo que introduce un elemento lineal de suma importancia dentro de la percepción de la obra. Los perfiles recortados de la cola aumentan, aún más, el papel fundamental de la línea. Este tipo de superficies rectas confiere rigidez a la talla, pero al mismo tiempo, le imprime fuerza y hasta cierta agresividad. En el caso de la pieza del museo londinense la rigidez se aminora, tanto por las ondas que describen su cuerpo, como por la decoración sobresaliente de las caras laterales. Las otras Xiuhcóatls, por sus superficies de doble curvatura, contrastan con la planimetría de la anterior, percibiéndose sus cuerpos como volúmenes hinchados cuyo efecto lineal se debe a la ornamentación.

El tipo de integración de los diversos componentes de las esculturas establece otra diferencia. En las tres serpientes de fuego enroscadas, tanto la cabeza como las garras, se fusionan al volumen principal formado por el cuerpo. En nuestra obra los componentes están interconectados, pero resultan fácilmente separables a la vista. Cada parte principal del monolito se labró como un volumen claramente definido y contenido en sí mismo; a este respecto es interesante observar cómo la juntura de los miembros con el cuerpo no constituye una transición suave, sino bien delineada y hasta abrupta. Dentro de la pieza hay, además, una relación axial peculiar, ya que el eje de la cabeza resulta perpendicular al del cuerpo, con lo que se diferencian, aún más, estos dos volúmenes principales. Por último, los símbolos que cubren a las Xiuhcóatls enroscadas funcionan como elementos lineales que le imprimen, asimismo, una textura singular a las superficies, mientras que en el ofidio aquí estudiado, los símbolos se perciben como formas fácilmente distinguibles de la superficie a la que se adhieren.

Varias características de la escultura permiten pensar que su diseño está inspirado más en relieves y códices que en la escultura en bulto. Estas características son: el cuerpo que no se enrosca ni anuda, los miembros bien diferenciados y las superficies planas con líneas de contorno muy marcadas. Los cuerpos serpentinos de los códices describen curvaturas, pero las sierpes ondulantes aparecen en relieves, pudiéndose citar como ejemplo el Cuauhxicalli de las Serpientes Emplumadas.

Creo de interés comparar nuestra obra con las Xiuhcóatls de Tenayuca. 
En ellas el cuerpo enroscado constituye un volumen muy compacto, mientras que el espacio penetra dentro de la boca y cresta, formando de esta última una greca calada (figura 9). Aunque las cabezas de estas serpientes sí muestran una relación íntima entre la masa y el espacio, no por ello tienen mucha semejanza con el ofidio del Museum of Mankind; la apariencia de las unas y de la otra es muy distinta, principalmente por la composición del cuerpo, pero también por el tipo de línea que define los contornos de la cabeza, muy angulosa en las de Tenayuca, y más suave y curva en nuestro ejemplar.

La Xiuhcóatl del Museum of Mankind posee otras cualidades formales que contribuyen a su hermosura. El cuerpo undoso, de curvas pronunciadas, le confiere una enorme vitalidad, y las formas orgánicas de la cabeza y del cuerpo se combinan armoniosamente con las formas geométricas, rígidas, de la cola. Las secciones trapezoidales, tan particulares de este reptil, ofrecen dos variantes: dentro del cuerpo se les señala por medio de superficies en relieve, sin afectar el contorno general del cuerpo, en cambio, en la cola definen su forma, distinguiéndose claramente dos segmentos trapezoidales y uno triangular. No queriendo darles una dureza excesiva a las diversiones trapezoidales, se curvan ligeramente sus contomos. Dentro de la concepción de la pieza resultan notables las oqueda. des de la cola que repiten, en pequeño, su configuración, dándole un claroscuro magnífico.

Como ya se mencionó anteriormente, nuestra escultura puede identificarse, por sus atributos, como una Xiuhcóatl. En seguida los enumero, comparándolos con los que muestran otras representaciones del mismo ser mítico. Hay que advertir que las serpientes de fuego no presentan constantemente los mismos elementos; así, por ejemplo, la Xiuhcóatl aquí analizada comparte características tanto con los códices, como con las piezas mexicas en bulto y en relieve. Para Seler, la cualidad singular de este animal fantástico es el hocico encorvado hacia arriba, pero no siempre se le dispone de esta manera. En mi opinión son más indicativos de su identidad el cuerpo dividido en segmentos trapezoidales y la cola carente de anillos óseos. Es importante agregar que en los códices hay mayor variabilidad en los elementos distintivos, mientras que dentro de las esculturas mexicas, de bulto y de relieve, las Xiuhcóatls tienen rasgos más constantes; es decir, estaba mejor definido su tipo iconográfico.

A las Xiuhcóatls, cuyo nombre significa serpientes de turquesa, se las representa generalmente con la mandíbula superior prolongada y vuelta hacia atrás o con una cresta sobre la cabeza. La sierpe tema de este 
artículo, pertenece al primer grupo; su hocico ostenta, además, ganchos pequeños y elementos simbólicos de las estrellas llamados comúnmente "ojos". ${ }^{2}$ Varios otros ejemplos pueden incluirse dentro de este tipo. En la vasija para pulque de la colección Bilimek, la víbora presenta un alargamiento semejante provisto de un gancho y de círculos concéntricos que pudieran ser también estrellas (figura 5). En el Códice Nuttall se la dibuja con la mandíbula superior volteada hacia atrás y adornada con ganchos y elementos cuadrangulares. Estos elementos, divididos a lo ancho en cuatro, probablemente sean una representación de los dientes (figuras 6 y 7). La Xiuhcóatl del Códice Vindobonensis muestra el hocico enrollado hacia atrás, sin elementos simbólicos. En el Códice Magliabecchi la mandíbula también se prolonga, estando cubierta de "ojos". Caso curioso es el oficio ilustrado en la página 49 del Códice Borgia: sobre el extremo de su mandíbula superior hay un gancho que se enrosca hacia el frente, guarnecido de "ojos" (figura 8).

E1 segundo grupo de Xiuhcóatl presenta, como ya se dijo, una cresta. A este grupo pertenecen las de Tenayuca, con sus crestas angulosas provistas de "ojos" (figura 9). Las sierpes de la Piedra del Sol tienen, asimismo, crestas con "ojos", aunque a diferencia de las anteriores, sus crestas nacen justo donde termina la boca (figura 10). Muy semejante a ellas es la enorme cabeza de una serpiente de turquesa que forma parte de la colección del Museo de Antropología de México (figura 11). Sobre un lado de la caja azteca, conocida con el nombre de Riva Palacio, se talló también una víbora con un especie de cuerno engalanado con círculas concéntricos (figura 12).

En los códices la serpiente de fuego adorna, principalmente, la espalda del dios Xiuhtecuhtli, pero también la de los dioses Huitzilopochtli y Tezcatlipoca (figura 13), En la mayoría de estos adornos la mandibula superior se curva hacia atrás y puede llevar tanto "ojos" (por ejemplo, las láminas 9 y 20 del Códice Borbónico y la lámina 77 del Códice Florentino), como círculos (lámina 9 del Tonalámatl de Aubin y lámina 23 del Borbónico) (figura 14). La lámina 24 del Códice TellerianoRemensis constituye una excepción por el cuerno pintado sobre la cabeza. Las insignias de los dioses, en ninguno de estos casos poseen los ganchos pequeños que hemos mencionado en relación con otros ejemplares.

Algunas serpientes de turquesa carecen tanto de la cresta como de la mandíbula deforme, pudiendo identificarse como tales por otros 
rasgos. Hay varias de este tipo dentro del Códice Borgia, entre ellas una que lleva sobre la mandíbula cuatro franjas agrupadas, acaso simbolizando los dientes (lámina 46 de dicho códice). De estas franjas quizá se originaron las barras que usualmente se representan sobre los cuerpos de las Xiuhcóatls mexicas hechas de piedra. Otros ejemplos son: la página 8 del Códice Laud y la 57 del Nuttall.

Algunas láminas del Códice Borgia muestran a la serpiente emplumada con los elementos conocidos como "ojos", y, por lo tanto, no pueden considerarse como exclusivos de las Xiuhcóatls.

Volviendo a la obra, tema de este artículo, dentro de su boca pueden observarse dos grandes colmillos curvos, típicos de las serpientes venenosas. En los códices del grupo Borgia y en los códices mixtecos los ofidios pueden poseer colmillos o carecer de ellos, además de que su posición varía. Dentro de las esculturas mexicas es frecuente encontrar tres colmillos cerca de las comisuras, adoptando estas últimas la forma de una voluta. Las tres Xiuhcóatls enroscadas, ya mencionadas, las de la Piedra del Sol y la enorme cabeza del Museo de México llevan los belfos cubiertos con dos franjas, una con círculos y otra con cuadretes. Las víboras de estas piezas se caracterizan, asimismo, por tener una voluta frente a la ceja, al igual que nuestro ejemplar.

Según mi parecer, la peculiaridad que distingue fundamentalmente a las serpientes de fuego es su cuerpo dividido en secciones trapezoidales, cuyo número es variable. Sin embargo hay sus excepciones; en algunas de las divisas llevadas por los dioses sobre la espalda se suprime el cuerpo de las culebras, dibujándose plumas en su lugar, y en algunas láminas de los códices ( 15 y 18 del Nuttall y 30 del Vindobonensis) el cuerpo se ve reemplazado por un gran círculo provisto de diseños diversos.

Las esculturas mexicas de piedra presentan segmentos trapezoidales engalanados con círculos y grupos de tres o cuatto barras, agregándose llamas en el caso de las sierpes de la Piedra del Sol (figura 15).

El cuerpo ondulante de la culebra del museo londinense tiene dos ganchitos sobre su dorso así como cuatro tiras anudadas. Estas tiras, de forma rígida como hechas de papel, ${ }^{3}$ no se dibujan de ordinario en los códices, excepto cuando se trata de atavíos de los dioses; sucede

3 Sahagún al describir la fiesta Panquetzaliztli nos habla de un sacerdote que "traía un hachón de teas muy largo, que llaman Xiuhcóatl; tenía la cabeza y la cola como culebra... traía la cola hecha de papel, dos o ties brazas de largo..."

(Sahagún, 1956, t. I, p. 212) . 
lo contrario en las obras mexicas de piedra, en las cuales aparecen a menudo. En cuanto a los ganchitos, probablemente aluden a las llamas, ya que se trata de una serpiente de fuego. Algunos ofidios del Códice Nuttall llevan este símbolo ígneo cerca de las garras o a los lados de la cola, y en el Códice Borgia salen de la boca o de su cuerpo. Sobre la nuca del reptil de la caja "Riva Palacio" hay una mariposa, símbolo del fuego.

La palabra xiuhhuitl puede tener, entre otras acepciones, la de "hierba". Aludiendo a este significado algunas Xiuhcóatls muestran una hilera de franjas con círculos pequeños, ya sea como parte de la cola o a sus lados. Los elementos labrados sobre la parte superior de la cola de nuestra pieząs pueden ser precisamente tallos de hierba. Éstos se encuentran también en la Piedra del Sol, caja "Riva Palacio", caja del Museo Nacional de Antropología que ostenta el cuerpo de la serpiente de turquesa sobre sus cuatro lados (figura 16), y, probablemente, en la vasija Bilimek. Rara vez llegan a pintarse en los códices; un ejemplo es el adorno de la espalda de Xiuhtecuhtli del Códice Borbónico.

Las colas de las serpientes de fuego, en los ejemplos que pude observar, nunca posecn anillos en la cola; es usual, en cambio, una terminación puntiaguda. La cola triangular es común a las tallas mexicas, lo mismo que a las insignias de los dioses, y es posible que simbolice un rayo solar. Los códices Nuttall y Vindobonensis presentan las víboras con cola en forma de cuchillo flanqueada por dos elementos curvos de posible indole flamígera. Entre las culebras del Códice Borgia la configuración de Ia cola es bastante variable, y hay un tipo que se decora con "ojos".

Por último, para confirmar el carácter fantástico de este animal se le agregaron las extremidades propias de los saurios. Nuestra escultura sólo tiene las delanteras, pero los ofidios de los códices mixtecos suelen dibujarse con las cuatro. Las serpientes de fuego del Códice Borgia pueden estar provistas de los miembros anteriores o carecer de ellos. En los atavíos de los dioses no existen, mientras que las patas delanteras son frecuentes entre las obras mexicas, como puede verse en la Piedra del Sol, la caja "Riva Palacio" y las Xiuhcóatls enroscadas. Los miembros de saurios, al igual que los "ojos", no son exclusivos de las serpientes de turquesa: la serpiente emplumada se pintó, en algunas láminas del Códice Borgia, con las extremidades anteriores de los saurios (lámina 11 de dicho códice).

Al revisar las fuentes me encontré con pocas referencias sobre esta sierpe mítica. El libro Ritos, sacerdotes y atavios de los dioses nos 
informa que es el nahualli, el doble de Huitzilopochtli. Las fuentes nos indican también su uso como arma. Así, el bien conocido mito que narra el nacimiento de Huitzilopochtli, dice: “... en llegando los dichos indios Centzonhuitznahua nació luego el dicho Huitzilopochtli... y dijo a uno que se llamaba Tochancalqui que encendiese una culebra hecha de teas que se llamaba Xiuhcóatl, y así la encendió y con ella fue herida la dicha Coyolxauhqui, de que murió hecha pedazos." * Sahagún, al relatarnos la fiesta Panquetzaliztli, habla de un hachón de teas con cabeza y cola de culebra que se quemaba al final de ciertas ceremonias. ${ }^{5}$ Durán menciona que Huitzilopochtli "llevaba en la mano derecha un báculo, labrado a manera de una culebra toda azul y ondeada". ${ }^{6}$

Varios estudiosos han investigado desde el siglo pasado acerca de los atributos de la Xiuhcóatl y su papel dentro de la mitología mexica. Entre ellos, Herman Beyer se ha referido extensamente al tema, principalmente en su artículo titulado: "El llamado Calendario Azteca".

Como se dijo anteriormente, la Xiuhcóatl forma parte del atavío de los dioses Xiuhtecuhtli, Huitzilopochtli y Tezcatlipoca. De estos tres se la identifica sobre todo con el primero, como puede notarse por el mismo nombre que lleva y porque ambos tienen un carácter ígneo. La palabra xiúhuitl puede significar año, hierba o turquesa según su pronunciación ${ }^{7}$ y, por tanto, el dios y la serpiente se relacionan con los tres conceptos. Aunque la Xiuhcóatl es la serpiente turquesa, la serpiente azul, se la pinta de rojo y de amarillo, los colores del fuego.

Según Beyer, la Xiuhcóatl es el firmamento azul por el cual pasa el sol durante su diario viaje; es, además, el complemento al zodiaco representado por Quetzalcóatl. No deja de extrañar que si se trata de una serpiente celeste diurna lleve sobre la piolongación de sus fauces varias estrellas que posiblemente configuren una constelación. Beyer lo explica de la manera siguiente: Quetzalcóatl, por su asociación con el zodiaco, está provisto de estrellas, las cuales se incluyeron también en la figura de la Xiuhcóatl para conferirle naturaleza celestial. "Una constelación como adorno simbólico de una sierpe de fuego no es explicable, pero sí es muy natural en una serpiente zodial que representa necesariamente figuras estelares." 8 Este carácter astronómico se manifiesta poco

4 Sahagún, op. cit., p 273 .

5 Ibid., p. 212

6 Durán, 1967, t. I, p. 19

7 Caso, 1971, p. 55.

8 Beyer, 1965 a, p. 232. 
en los códices mixtecos, en los cuales las Xiuhcóatls forman parte habitual del atavio de personajes históricos, además de ser toponímicos, en ambos casos desprovistos de "ojos". Como excepciones tenemos: la lámina 30 del Códice Vindobonensis, en la cual se presenta a la sierpe cargando lo que Beyer interpreta como el disco solar, y la página 31 del Nuttall, donde se la pinta asociada a un pequeño altar guarnecido con "ojos".

No es posible saber desde qué momento nació en la mente indígena la concepción de una sierpe mítica de índole flamígera, sólo podemos rastrear los elementos que la llegaron a caracterizar dentro del Posclásico Tardío. No hay entre los olmecas representaciones de este tipo de serpientes; tampoco encontramos su imagen en el arte teotihuacano, en el cual, en cambio, se define otra forma iconográfica serpentina; me refiero a la serpiente emplumada. Alfonso Caso niega la existencia de la Xiuhcóatl en Teotihuacan; Davies, por su parte, opina que la serpiente de turquesa, por ser de color azul, pudo haber estado relacionada con Tláloc y con Quetzalcóatl; pero, repetimos, no hay víboras dentro del arte teotihuacano con los rasgos típicos de la serpiente de fuego.

Caso, al estudiar la escrituxa glífica de Xochicalco, encontró un glifo al que denominó $x i$, consistente en varios trapecios invertidos, el cual, según su opinión, pudiera ser el antecedente de las secciones trapezoidales del cuerpo de la serpiente de turquesa. ${ }^{9}$

Las cariátides de Tula llevan en las espaldas adornos circulares compuestos de un rostro humano rodeado de cuatro serpientes. Algunos autores las identifican como Xiuhcóatls, basándose probablemente, ya que no lo especifican, en que su mandíbula superior se curva hacia atrás describiendo un contorno anguloso; ${ }^{10}$ sin embargo, carecen de los otros elementos típicos que ya hemos apuntado. Otros investigadores hablan de su existencia en Ghichén Itzá. Efectivamente, en el templo del Chac Mool de este sitio, se descubrieron pinturas de serpientes de cuerpo segmentado a lo ancho, con patas delanteras de saurio y sin anillos en la cola (figura 17). No es posible saber, sin embargo, si se trata de una Xiuhcóatl o de un Quetzalcóatl, puesto que ambos presentan, en ciertos casos, dichos rasgos. Alfonso Caso acepta la existencia en Chichén Itzá de Xiuhcóatls asociadas con el sol. ${ }^{11}$

Tanto Beyer, como Krickeberg, pensaban que la imagen de la serpiente de turquesa se había derivado de la de Quetzalcóatl. En las

9 Caso, 1965, p. 174-175, fig 11

10 Acosta, 1961; Dutton, 1955.

11 Caso, 1941, p. 92. 
láminas 29, 30 y 31 del Códice Borgia se dibujó un extraño ser de cuerpo serpentiforme y rostro con pico, el cual presenta una cresta enroscada con "ojos"; éstos aparecen también en su cuerpo. En ocasiones este ser posee miembros de saurios. Por sus rasgos pudiera tratarse de un Ehécatl; Seler lo identifica precisamente como el dios del viento. Existe la posibilidad de que la serpiente de turquesa provenga de este tipo de representaciones.

El origen de la serpiente de turquesa quizá deba buscarse fuera del altiplano, ya sea dentro de la zona maya o en la oaxaqueña. ${ }^{12}$ Nicholson opina lo siguiente: "el tipo de cuerpo segmentado podría conectar [a la Xiuhcóatl] en su más remoto origen con el monstruo celestial-terrestre de las tierras bajas mayas, al cual designa Thompson como Itzam Na." ${ }^{13}$ En efecto, en algunas representaciones de dicho ser el cuerpo seccionado se ąlarga, volviéndose serpentiforme, pero conservando los miembros de los saurios. Para Thompson los Itzam son monstruos, tipo dragones, que ocasionalmente muestran cuerpos serpentinos. Uno de los aspectos de Itzam $\mathrm{Na}$, relacionado con lo terrestre y denominado Itzam Cab, era también un dios ígneo. ${ }^{14}$

En Oaxaca la serpiente de fuego fue un tema, si no muy popular. sí recurrente, sobre todo en los códices. En el Nuttall, pintado según Caso poco antes de 1438, el cuerpo de la serpiente está segmentado formando divisiones trapezoidales, carece de anillos en la cola, tiene miembros de lagarto y su mandíbula se alarga y se enrosca pronunciadamente hacia atrás. En algunas ilustraciones salen llamas de sus garras (láminas 15 y 18). El rasgo puntiagudo de su cola, semejante a un cuchillo, pudo haberse trasformado posteriormente en rayo solar, tal como se observa en los ejemplares mexicas. Una Xiuhcóatl, modelada en estuco, fue descubierta en la tumba 1 de Zaachila (figura 18). Como sucede frecuentemente en esta zona aparece como parte del atavío de un personaje, al cual se refiere Caso como "el sacrificador TortugaXiuhcóat1". La cabeza de la sierpe es el tocado y su mandíbula superior se dobla en ángulo hacia atrás. El cuerpo del personaje se cubrió con un caparazón de tortuga del cual sale, a un lado, la cola compuesta de secciones trapezoidales y de un elemento puntiagudo. La página 44 del Códice Nuttall ilustra una figura humana con el mismo atuento.

12 No es posible considexar como antecedentes a las Xiuhcóatls de Tenayuca, dado que corresponden probablemente a la quinta o sexta épocas, cuando el sitio estaba bajo el dominio mexica; ver Marquina, 1964, y Piña Chán, 1976.

13 Nicholson, 1973.

14 Thompson, 1970, p. 209-232. 
La figura parece estar muerta pues su ojo está cerrado, encontrándose colocado además frente al templo del Dios de la Muerte (figura 19). También se le pintó en la página $19 \mathrm{del}$ mismo códice y en la 12 , donde funciona como toponímico. Alfonso Caso en sus comentarios al Códice Selden incluye una lista de otros ejemplares de los códices mixtecos. Aunque este estudio de la Xiuhcóatl no pretende ser exhaustivo, logra apuntar una serie de problemas acerca del origen y evolución de este ser mítico, además de mostrar la gran diversidad de sus representaciones, entre las cuales sobresale como una estupenda creación artística la serpiente de fuego del Museum of Mankind.

\section{BIBLIOGRAFIA}

Acosis, J

1961 "La indumentaria de las cariátides de Tula". Homenaje a Pablo Martinez del Rio, p. 221-228, México.

BEYER, H.

1965a "El llamado Calendario Azteca". Mito y simbolismo del México antiguo, El México antiguo, t. x, p. 134-256. Sociedad Alemana Mexicanista, México.

1965b "Los simbolos de las estrellas en el arte religioso de los antiguos mexicanos." Mito y simbolismo del México antiguo. El México antiguo, t. x, p. 44-48. Sociedad Alemana Mexicanista, México.

Burland, C. A.

1948 Art and Life in Ancient Mexico. Bruno Cassirer, Oxford.

Caso, A.

1941 "El complejo arqueológico de Tula y las grandes culturas indígenas de México." Revista Mexicana de Estudios Antropológicos, vol. 5, pp. 85-95, México.

1960 Interpretación del Códice Bodley. Sociedad Mexicana de Antropología, México.

1964 Interpretación del Códice Selden 3135 (A-2). Sociedad Mexicana de Antropología, México.

1966a "Dioses y signos teotihuacanos". Teotihuacan. Onceava Mesa Redonda, vol. I, p. 249-279. Sociedad Mexicana de Antropología, México.

1966b Interpretación del Código Colombino. Sociedad Mexicana de Antro. pología, México.

1967 Los calendarios prehispánicos. Universidad Nacional Autónoma de México, México.

1971 El Pueblo del Sol. Fondo de Cultura Económica, México.

CóDICES BEKER I/II

1964 Comentario, descripción y corrección de Karl A. Nowotny. Instituto Nacional de Antropología e Historia, México. 


\section{CoDEX Borbonicus}

1974 Códices Selecti, vol. xurv. Akademische Druck-u. Verlagsanstalt, Graz, Austria.

CODEX FEJ J́RVÁRY-MAYER

1971 Códices Selecti, vol. xxvi. Akademische Druck-u. Verlagsanstalt, Graz, Austria.

\section{CoDex LAUd}

1966 Códices Selecti, vol xi. Introduction C. A. Burland. Akademische Druck-u. Verlagsanstalt, Graz, Austria.

\section{Codex Magliabechiano}

1970 Códices Selecti, vol. xxIII. Akademische Druck-u. Verlagsanstalt, Graz, Austria.

\section{CoDex Nu'TtaLL}

1975 A Picture Manuscript from Ancient Mexico. Ed. Zelia Nuttall. Dover Publications, Inc., New York.

\section{Códice Telleriano-Remensis}

1964 Antigüedades de México basadas en la recopilación de Lord King. sborough, vol. I. Secretaría de Hacienda y Crédito Público, México.

CoDEX VATICANUS 3773

1972 Códices Selecti, vol. xxxvi. Akademische Druck-u. Verlagsanstalt, Graz, Austria.

Codex Vindobonensis Mexicanus 1

1963 Códices Selecti, vol v. Akademische Druck-u. Verlagsanstalt, Graz, Austria.

Davies, $\mathrm{N}$

1977 The Toltecs Until the Fall of Tula. University of Oklahoma Press, Norman.

DƯRÁN, D.

1967 Historia de las Indias de Nueva España y Islas de Tierra Firme. A. M. Garibay K. ed. 2 vols. Ed. Porrúa, Mexico.

Duiton, B. $P$.

1955 "Tula of the Toltec." El Palacio, vol. 62, núm. 7-8, p. 195-251. School of American Research, Archaeological Institute of America.

\section{Escultura Prehispánica}

1958 "Escultura Prehispánica Mexicana." Artes de México, vol. IIr, núm 17, Mexico.

JoRALEMon, D. D.

1976 "The Olmec Dragon: a study in Pre-Columbian Iconography". Origins of Religious Art and Iconography in Preclassic Mesoamerican, H. B. Nicholson, ed., pp. 27-72, U.C.L.A. Latin America Center Publications, Ethnic Arts Council of Los Angeles, Los Angeles.

KRICKEEBERG, W.

1961 Las antiguas culturas mexicanas, Fondo de Cultura Económica, México. 
MARQUina, I,

1964 "Arquitectura Prehispánica." Memorias, núm. I del Instituto Nacional de Antropología e Historia, México.

Morris, E. $\mathrm{H}_{n}$, J. Cirarlot y A. A. Morris

1931 "The Temple of the Warriors at Chichén Itzá, Yucatán." 2 vols. Carnegie Institution, Publications 406, Washington, D. C.

NAvARrete, C.

1973 La Piedra del Sol. Museo Nacional de Antropologia, México.

Nicholson, H. B.

1973 "The Late Pre-Hispanic Central Mexican (Aztec) Iconographic System." The Iconoraphy of Middle American Sculpture, p. 73-97, The Metropolitan Museum of Ait, New York.

NoRIEGA, R.

1956 La Piedra del Sol y 16 monumentos astronómicos del México antiguo. Simbolos y clazes. Ed. Superior, México.

PADDock, J., ed.

1970 Ancient Oaxaca. Stanford University Press, California.

Palacios, E. J.

1942 "Hallazgos arqueológicos efectuados en México"" Revista Mexicana de Estudios Antropológicos, vol. vi, pp. 51-61, México.

PIÑA CHÁN, R.

1976 "Los Chichimecas y los mexicas." Los señorios y estados militaristas, p. 159-182, Instituto Nacional de Antropología e Historia, México.

RITOS, SACERDOTES Y ATAVíos DE LOS DIOSES

1958 "Ritos, sacerdotes y atavíos de los dioses." M. León-Portilla, ed. y traductor. Textos de los informantes de Sahagún, núm. 1 . Instituto de investigaciones Históricas, UNAM, México.

ROGERS, L R.

1969 "Sculpture." The Appreciation of the Arts/2. Oxford University Press, London.

SAHAGÚN, B.

1956 Historia general de las cosas de la Nueva España A. M. Garibay, ed. y traductor. 4 vols. Ed. Porrúa, México.

SELER, E.

s. "Cajas de Piedra (tepetlacalli) con representaciones del sacrificio y otros monumentos análogos." Colección de disertaciones relativas a la filologia y arqueologia americanas, t. 2, segunda parte, p. 318-359. Publicado en alemán en 1904. Copia mecanoscrita.

s. f. "Excavaciones en el lugar en que estuvo el Templo Mayor de México." Colección de disertaciones relativas a la filologia y arqueologia americana, t. 2, segunda parte, p. 1-113. Publicado en alemán en 1901. Copia mecanoscrita.

s. f. "La vasija de pulque de la colección Bilimek." Colección de diserta- 
ciones relativas a la filologia y arqueología americana, t. 2, segunda parte, p. 120-151. Publicado en alemán en 1902. Copia mecanoscrita.

s. f. "Tablero de Cedro de Tikal" Colección de disertaciones relativas a la filología y arqueología americanas, t. I, tercera parte. Publicado en en alemán en 1900 . Copia mecanoscrita.

1963 Comentarios al Códice Borgia. 3 vols. Fondo de Cultura Económica, México.

\section{TENAYUCA}

1932 Trabajos de la Dirección de Estudios Prehispánicos del Departamento de Monumentos de la Secretaria de Educación Pública, núm. 6, Instituto Panamericano de Geografía e Historia.

ThOMPSON, J E.

1970 Maya History and Religion. University of Oklahoma Press, Norman.

Para abreviar la bibliografía no incluí en ella los informes de Jorge Acosta sobre sus excavaciones en Tula, los cuales consulté para determinar la presencia de las Xiuhcóatls en este centro ceremonial. Estos reportes aparecieron en la Revista Mexicana de Esiudios Antropológicos, t. v, viI y xIV, y en los Anales del Insiituto Nacional de Antropologia e Historia, sexta época, t. vuI, $\mathrm{Ix}$, XIII y XVt. 
DOI: http://dx.doi.org/10.22201/iie.18703062e.1978.48.1099 
DOI: http://dx.doi.org/10.22201/iie.18703062e.1978.48.1099

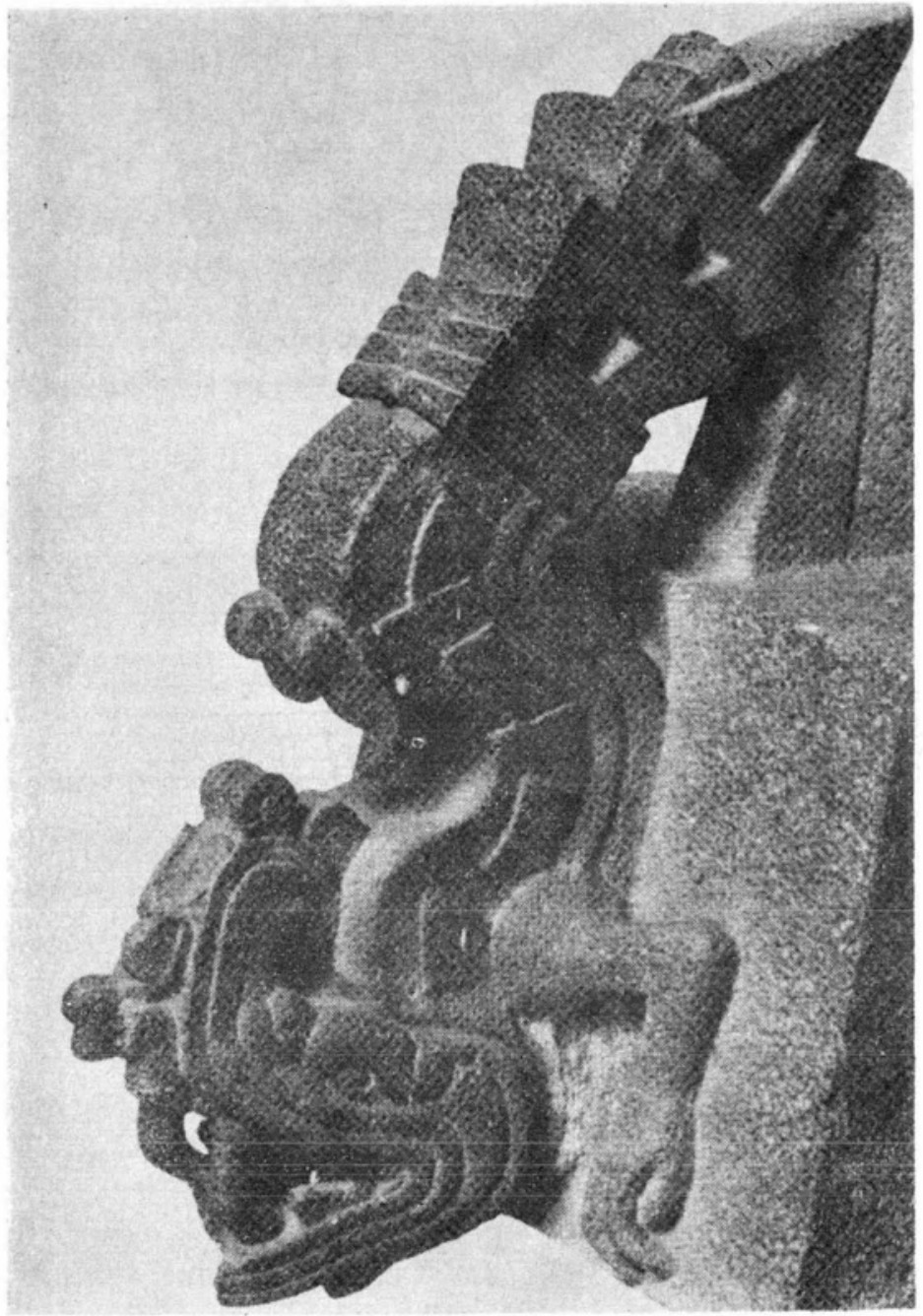

Figura 1. Xiuhcóatl del Museum of Mankind. Foto tomada de Burland, 1948. 
DOI: http://dx.doi.org/10.22201/iie.18703062e.1978.48.1099

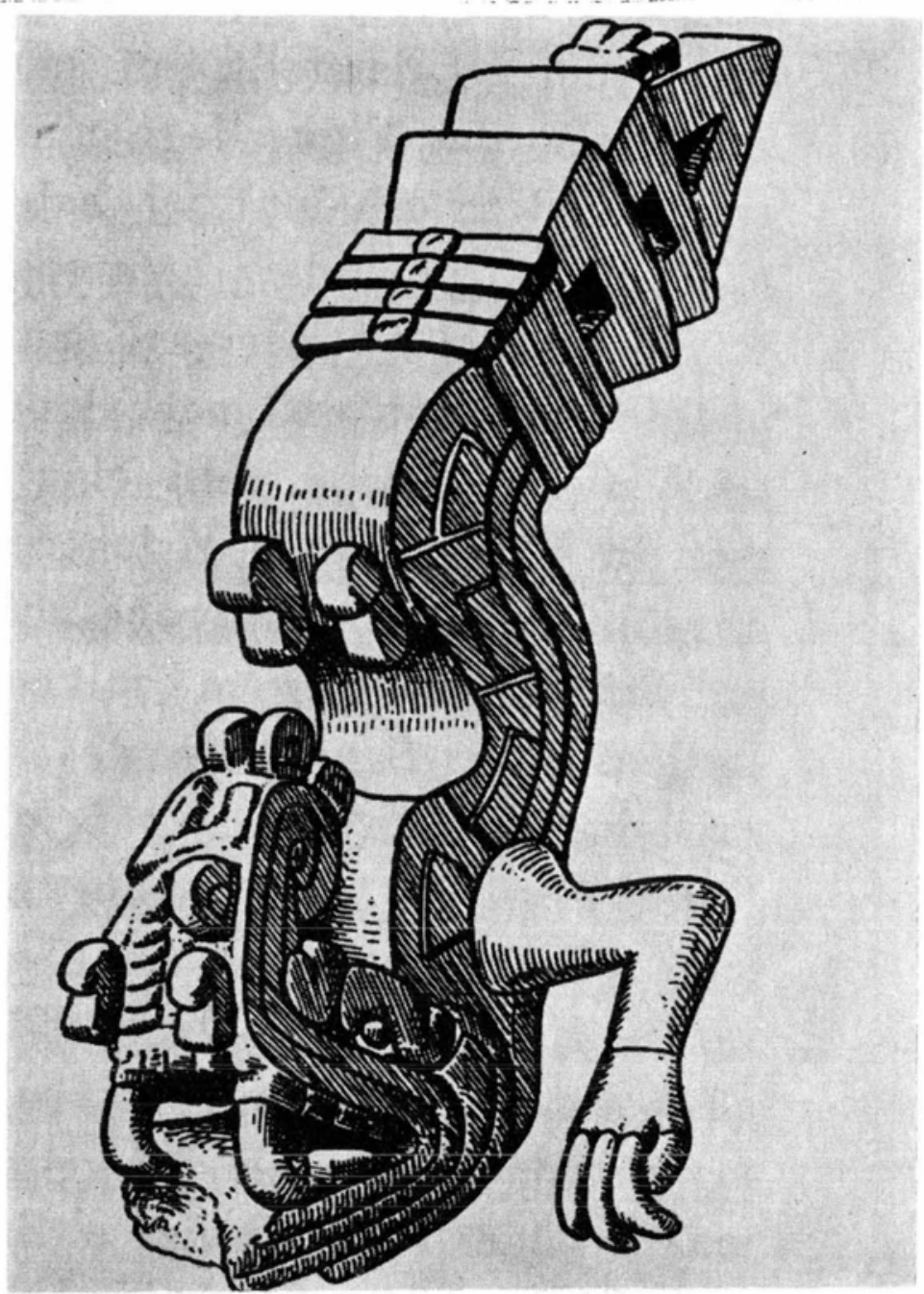

Figura 2. Dibujo de la Xiuhcóatl del Museum of Mankind. Tomado de Seler. 
DOI: http://dx.doi.org/10.22201/iie.18703062e.1978.48.1099

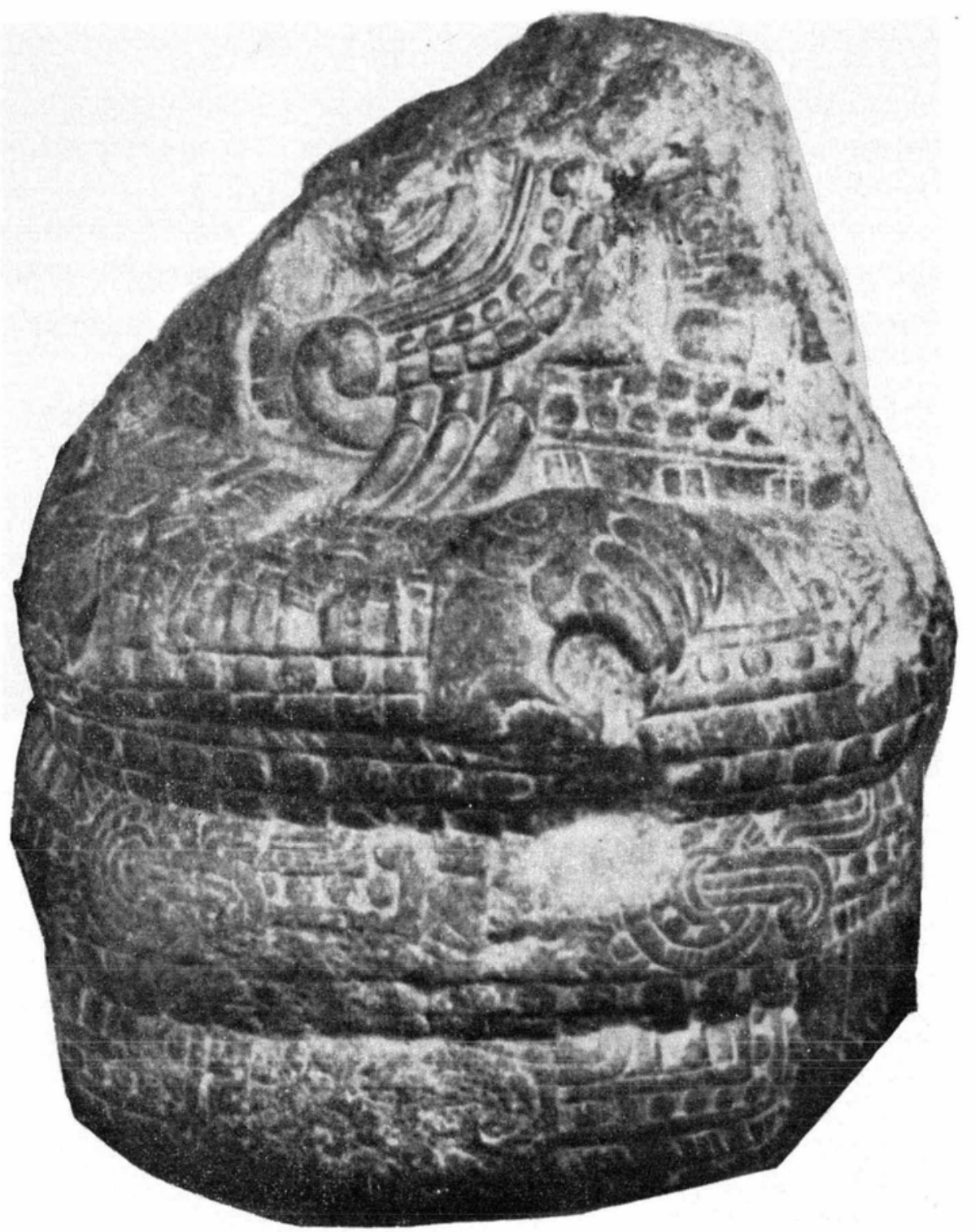

Figura 3. Serpiente de Fuego. Museo Nacional de Antropología e Historia. 
DOI: http://dx.doi.org/10.22201/iie.18703062e.1978.48.1099

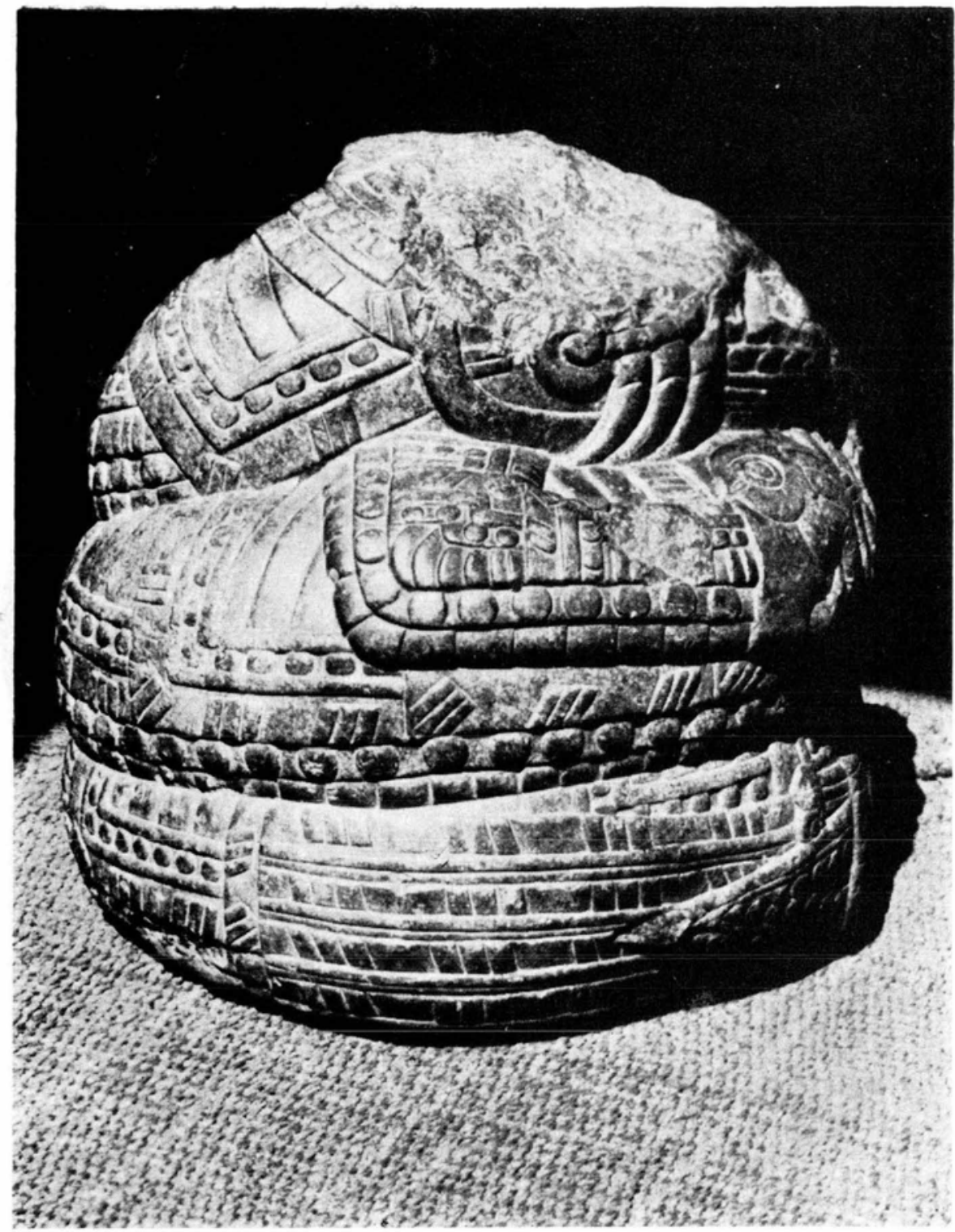

Figura 4. Serpiente de Fuego. Puede notarse la forma triangular de la cola. 
DOI: http://dx.doi.org/10.22201/iie.18703062e.1978.48.1099

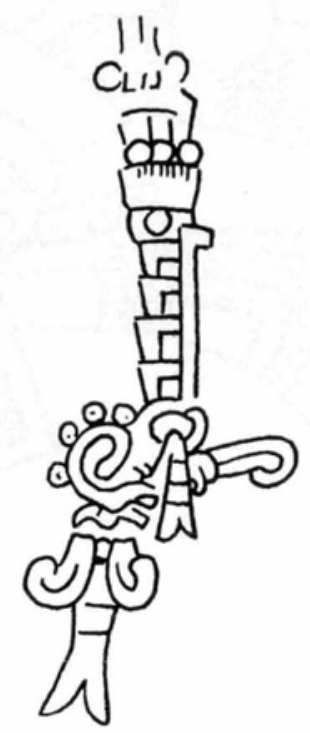

Figura 5. Xiuhcóatl, detalle de la vasija de la Colección Bilimek, Museum für Völkerkunde, Viena. Dibujo tomado de Seler. 


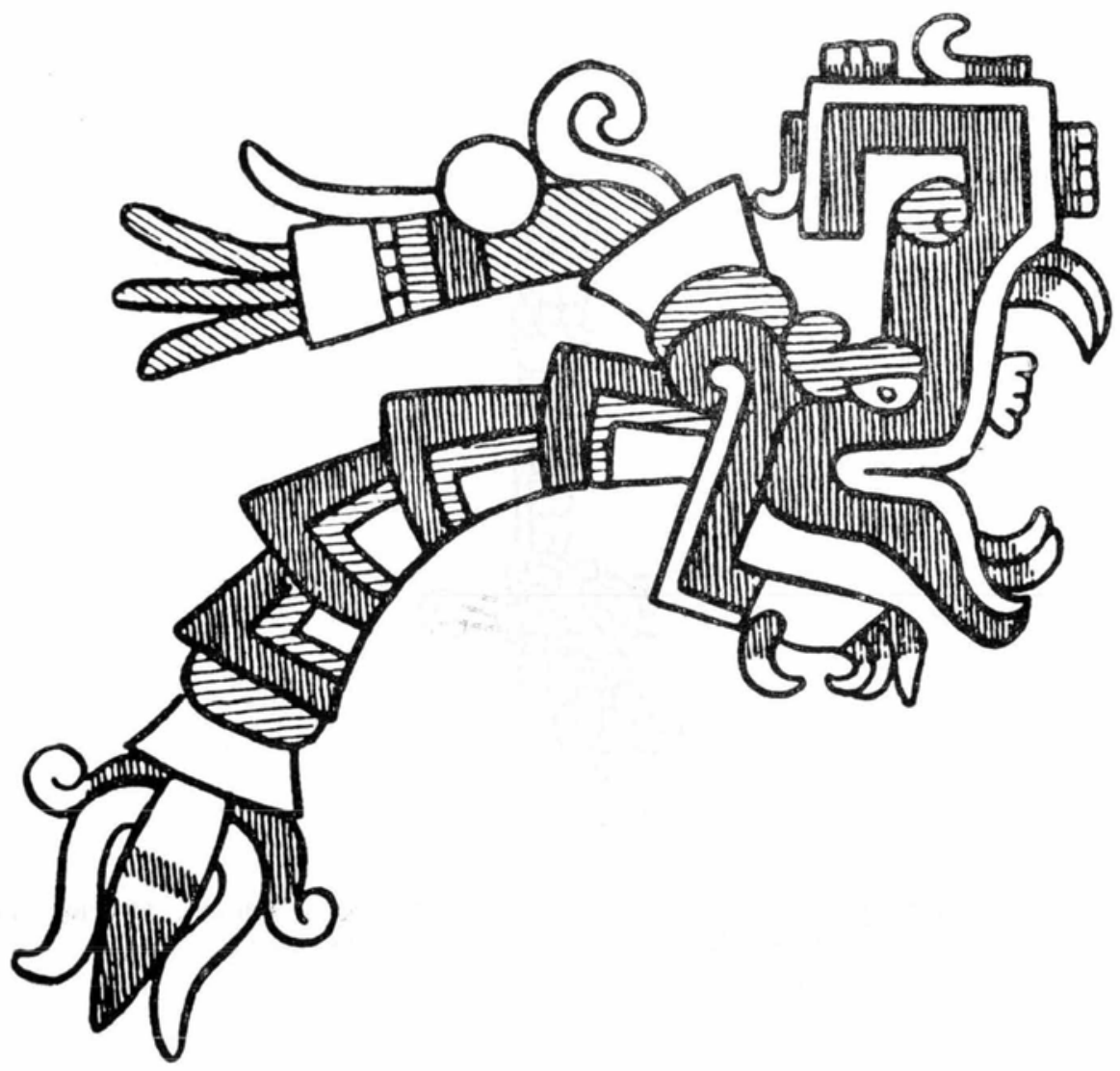

Figura 6. Xiuhcóatl, lámina 76 del Códice Nuttall. Dibujo tomado de Seler. 
DOI: http://dx.doi.org/10.22201/iie.18703062e.1978.48.1099

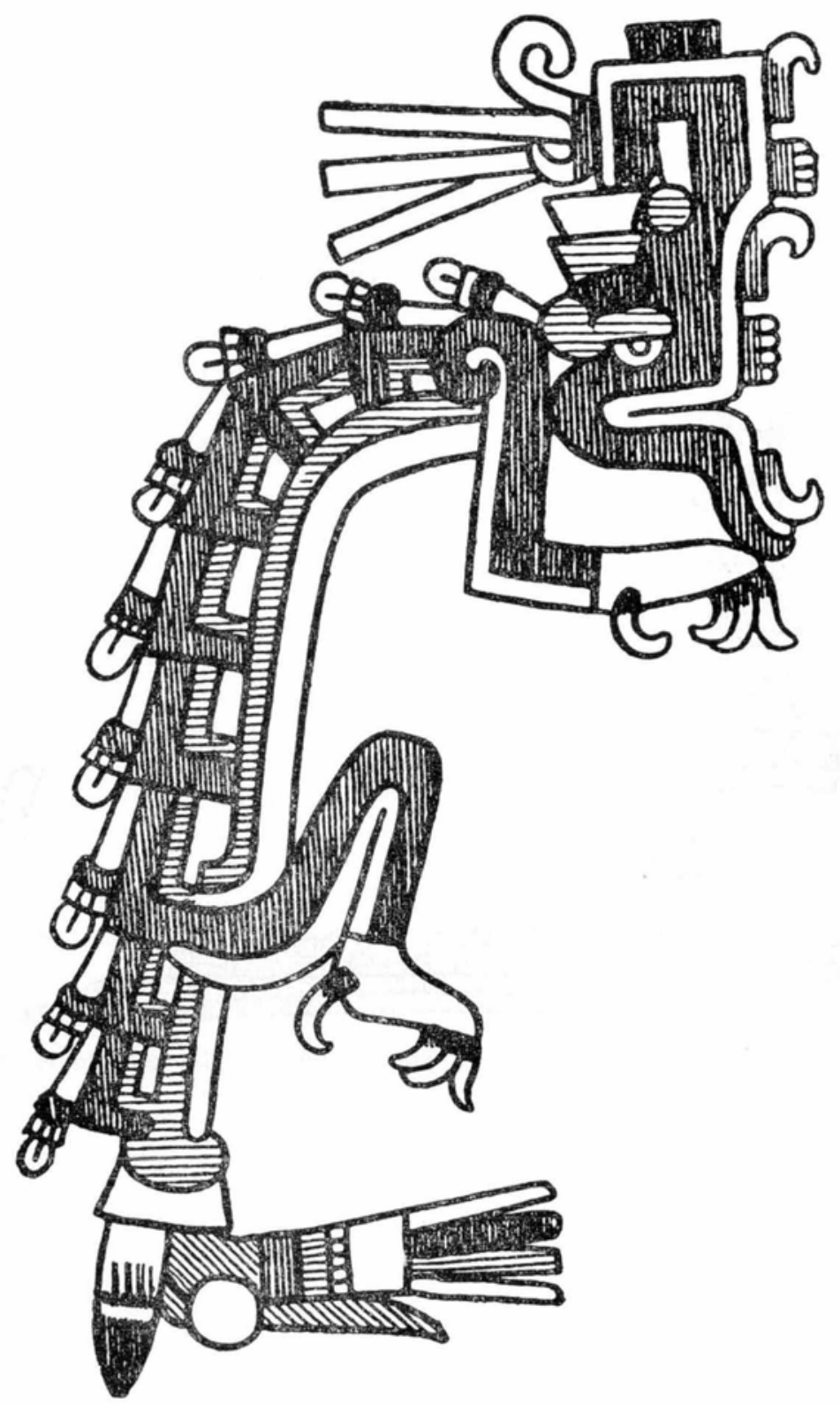

Figura 7. Xiuhcóatl, lámina 79 del Códice Nuttall. Dibujo tomado de Seler. 
DOI: http://dx.doi.org/10.22201/iie.18703062e.1978.48.1099

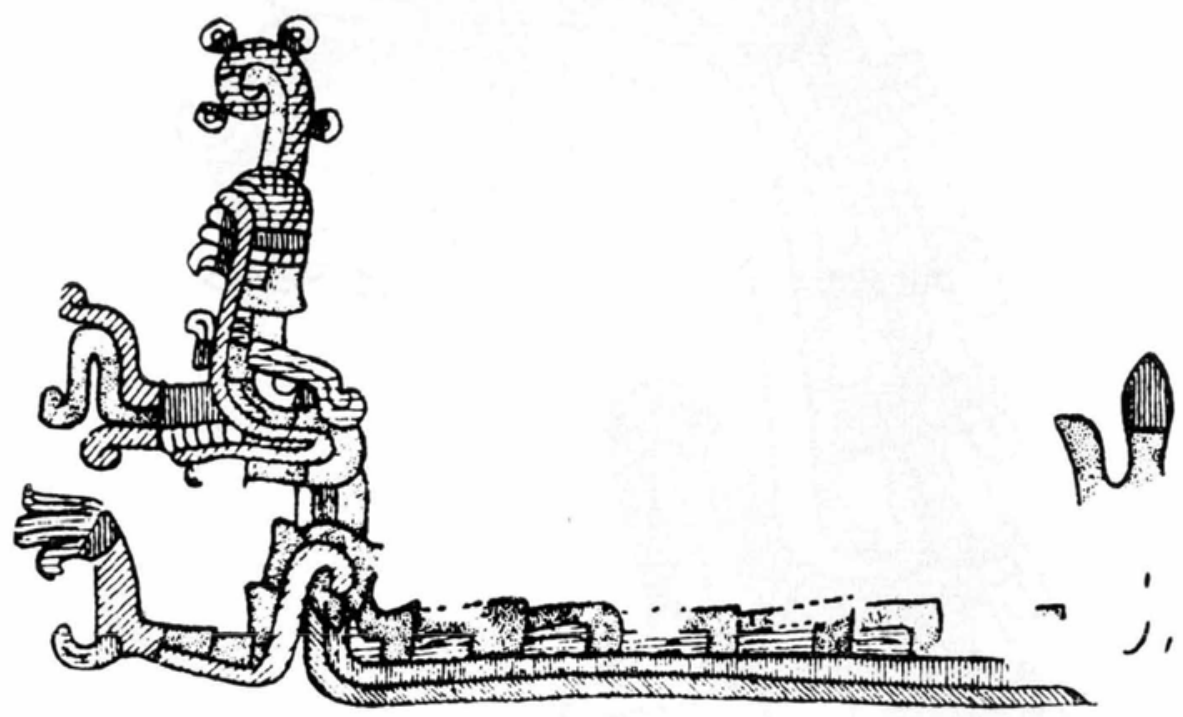

Figura 8. Xiuhcóatl, lámina 49 del Códice Borgia. Dibujo tomado de Beyer. 
DOI: http://dx.doi.org/10.22201/iie.18703062e.1978.48.1099

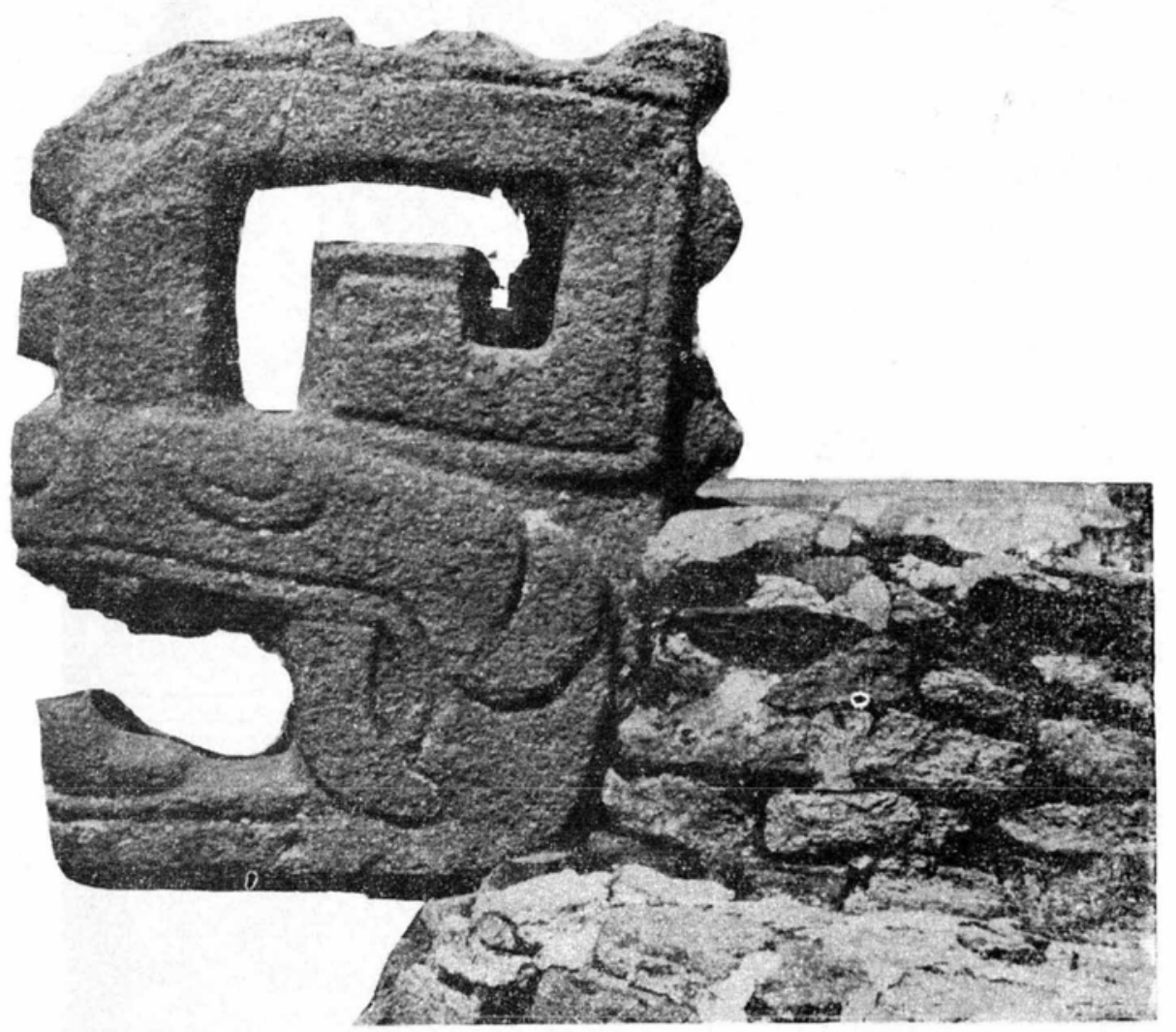

Figura 9. Xiuhcóatl del centro ceremonial de Tenayuca. 


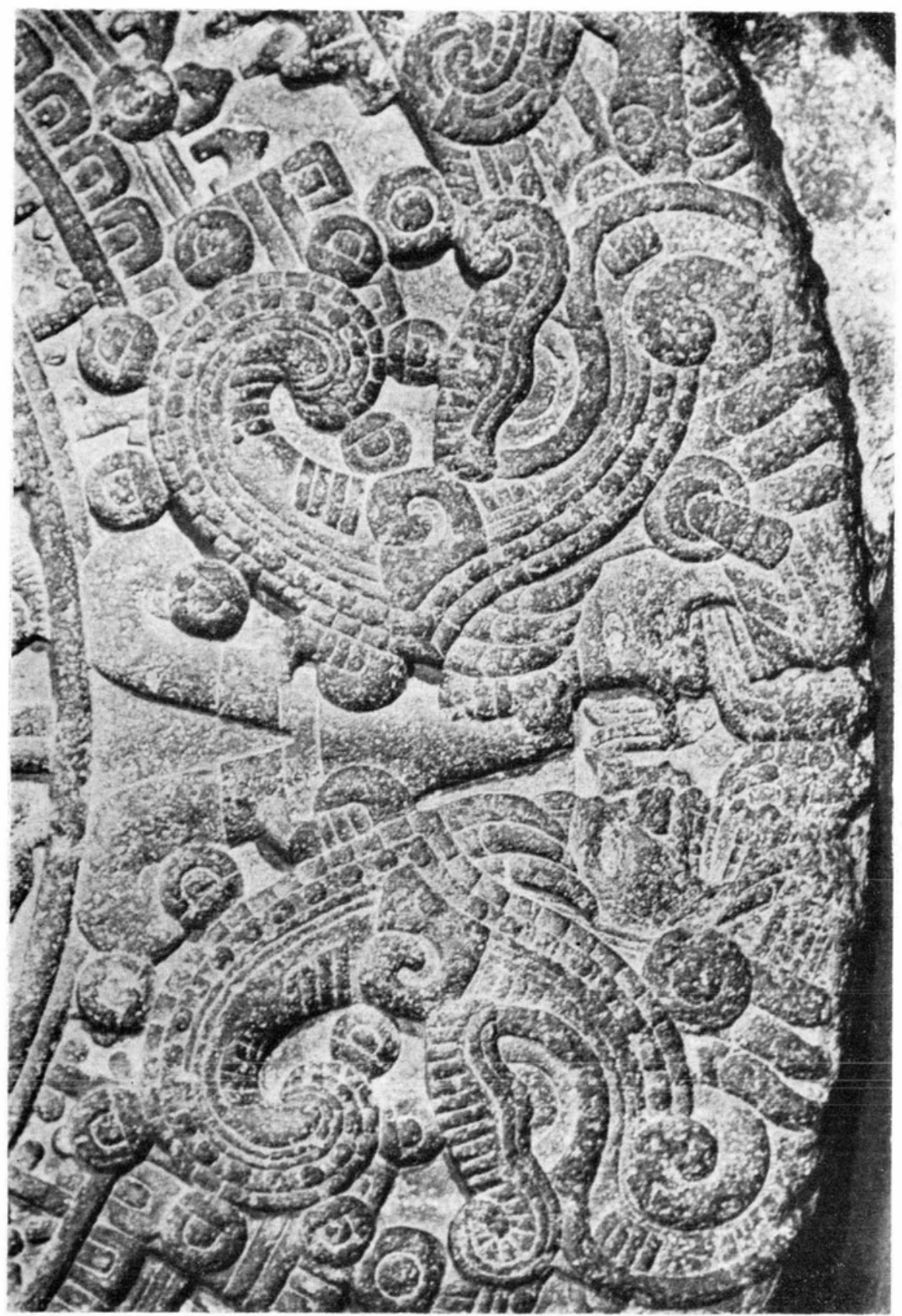


DOI: http://dx.doi.org/10.22201/iie.18703062e.1978.48.1099

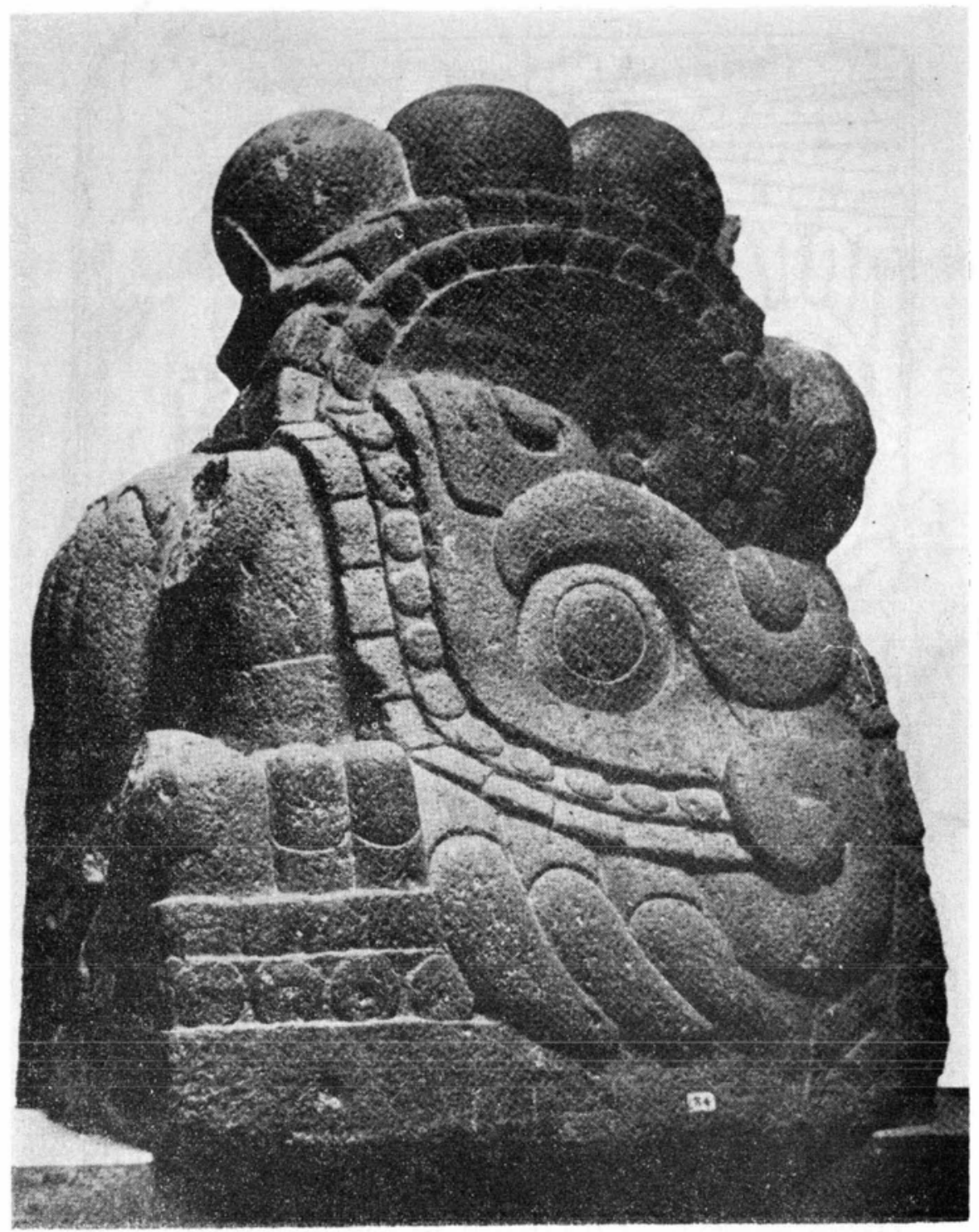

Figura 11. Cabeza de Xiuhcóatl. Museo Nacional de Antropología. 


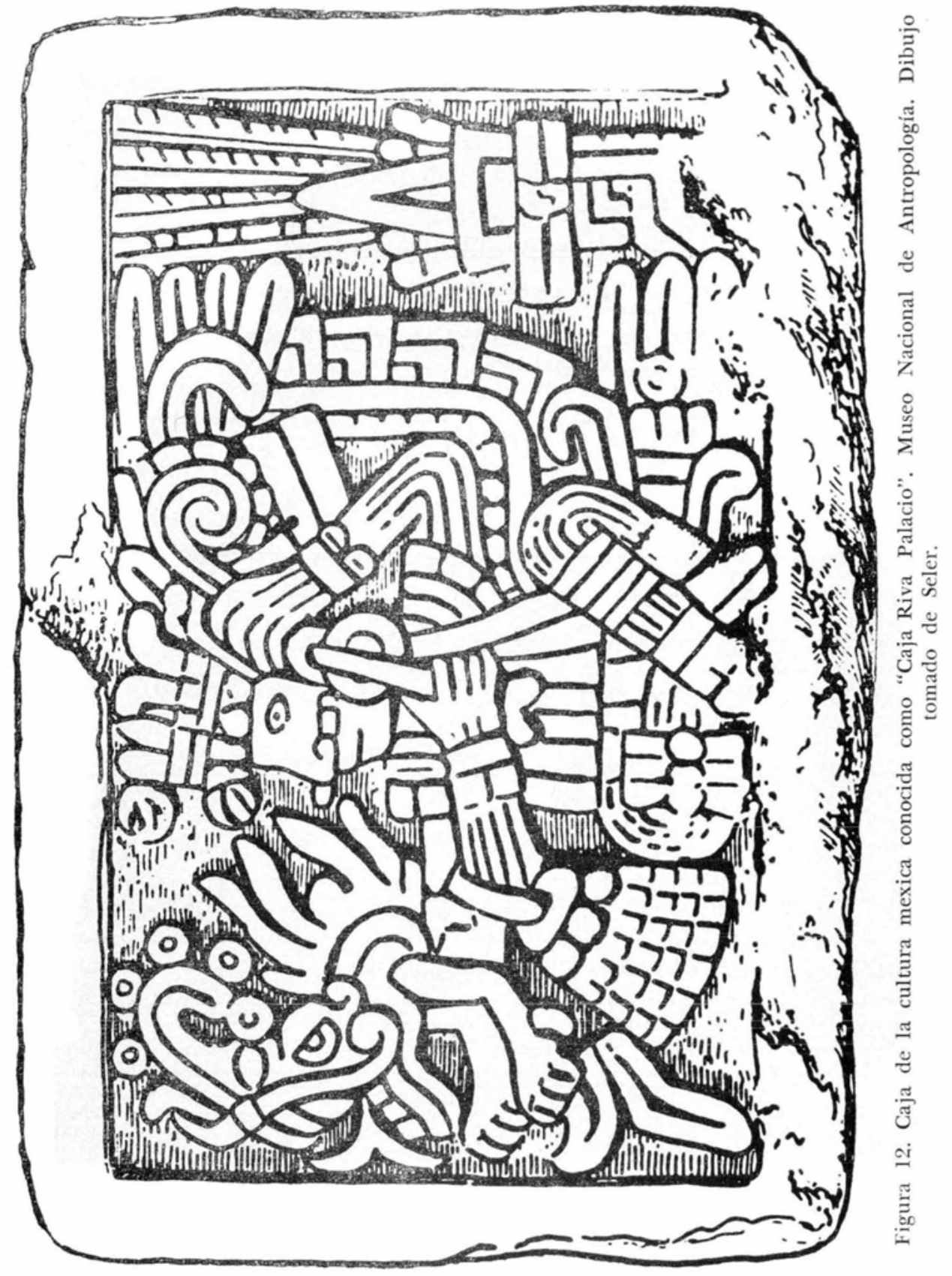



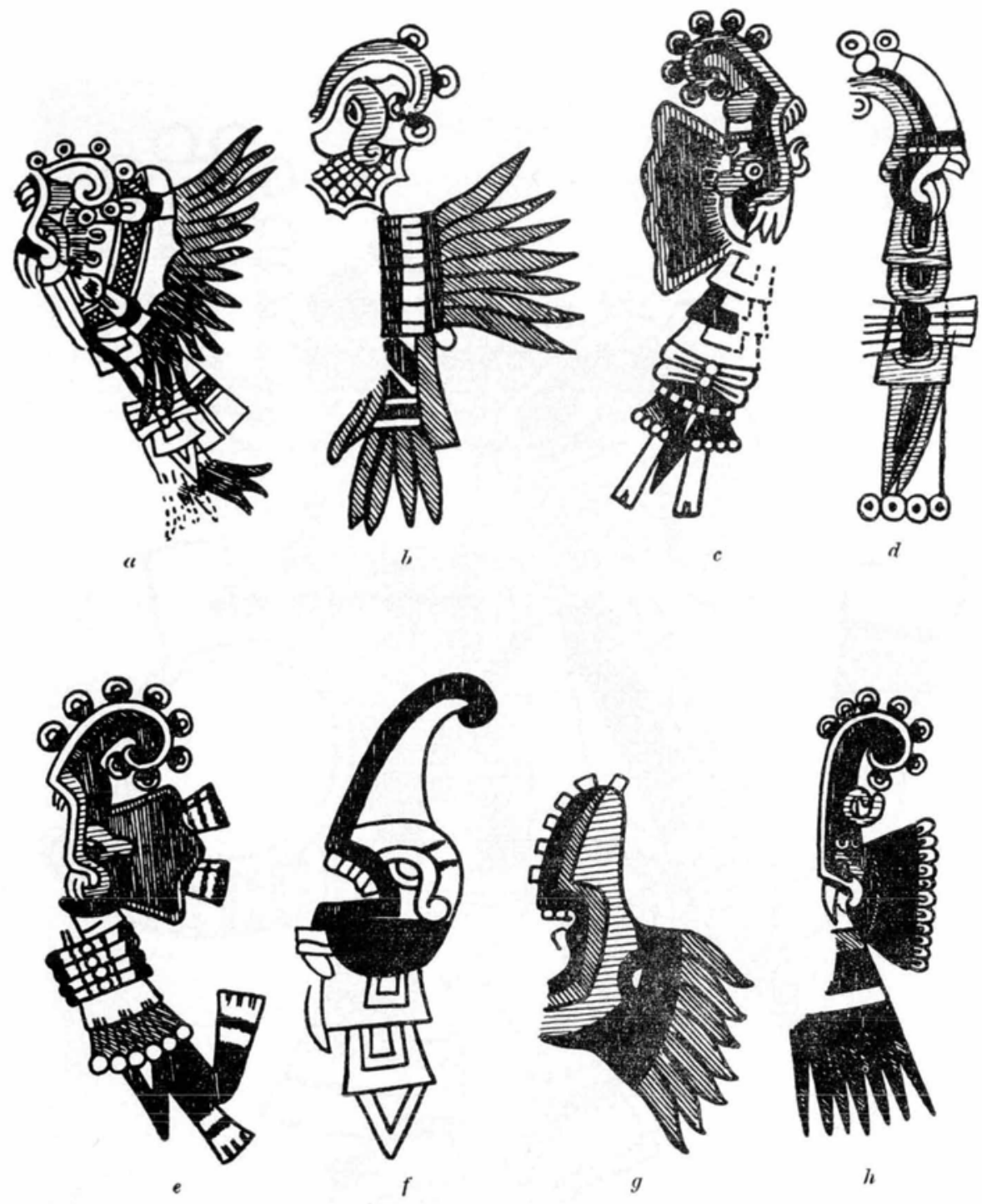

Figura 13. La Xiuhcóatl llevada como adorno de la espalda de los dioses. Como atavio de Xiuhtecuhtli: a) Códice Telleriano Remensis, lámina 24; b) Códice Florentino, lámina $77 ; c$ ) Códice Borbónico, lámina $20 ; d$ ) Tonalámatl de Aubin, lámina 9; e) Códice Borbónico, lámina 9; f) Códice Matritense del Real Palacio. Como atavio de Huitzilopochtli; g) Códice Matritense del Real Palacio. Como atavío de Tezcatlipoca; $h$ ) Códice Borbónico, lámina 22. Dibujos tomados de Seler. 
DOI: http://dx.doi.org/10.22201/iie.18703062e.1978.48.1099

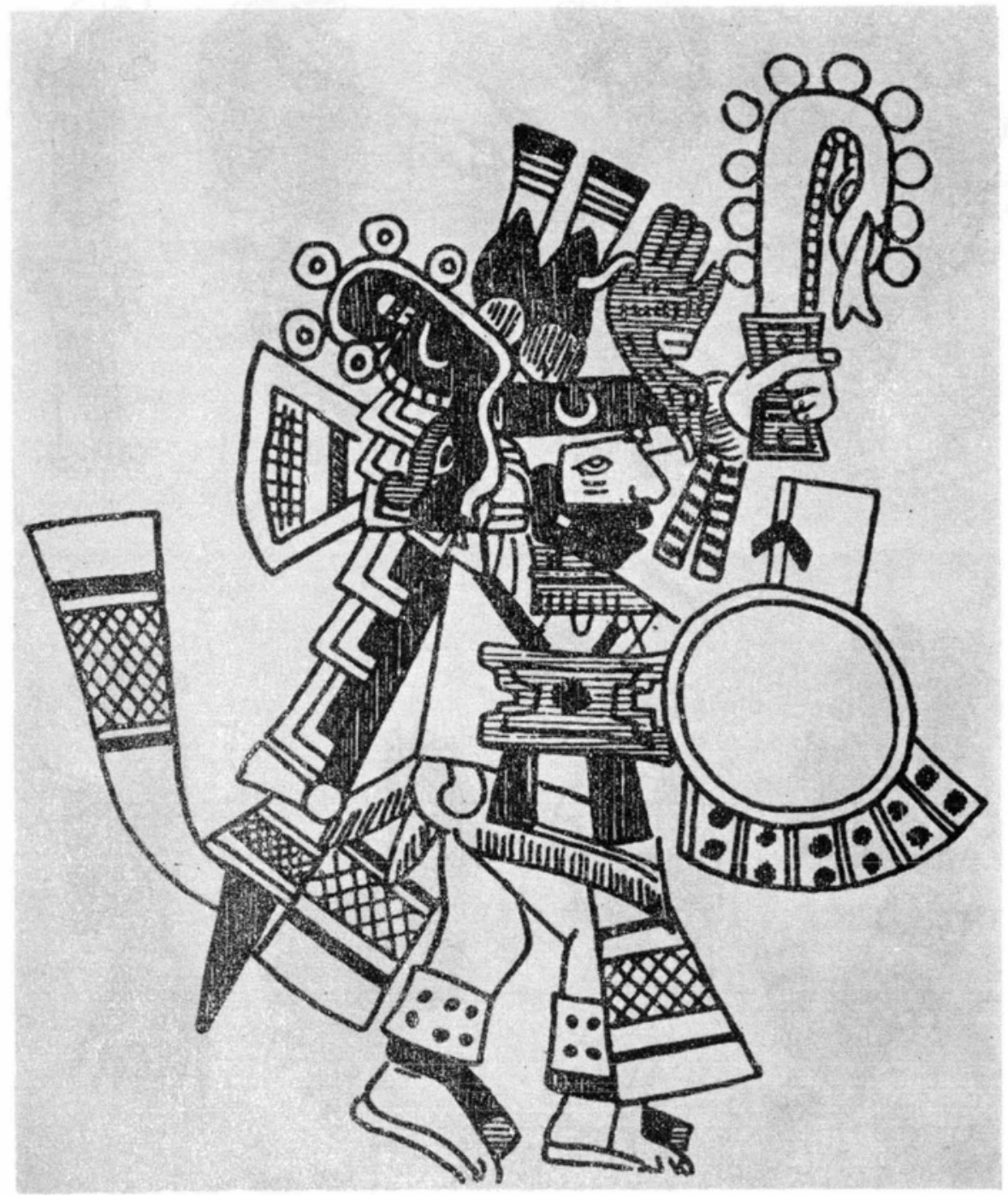

Figura 14. Xiuhtecuhtli con la Serpiente de Fuego en la espalda. Códice Borbónico, lámina 23. Dibujo tomado de Seler. 
DOI: http://dx.doi.org/10.22201/iie.18703062e.1978.48.1099

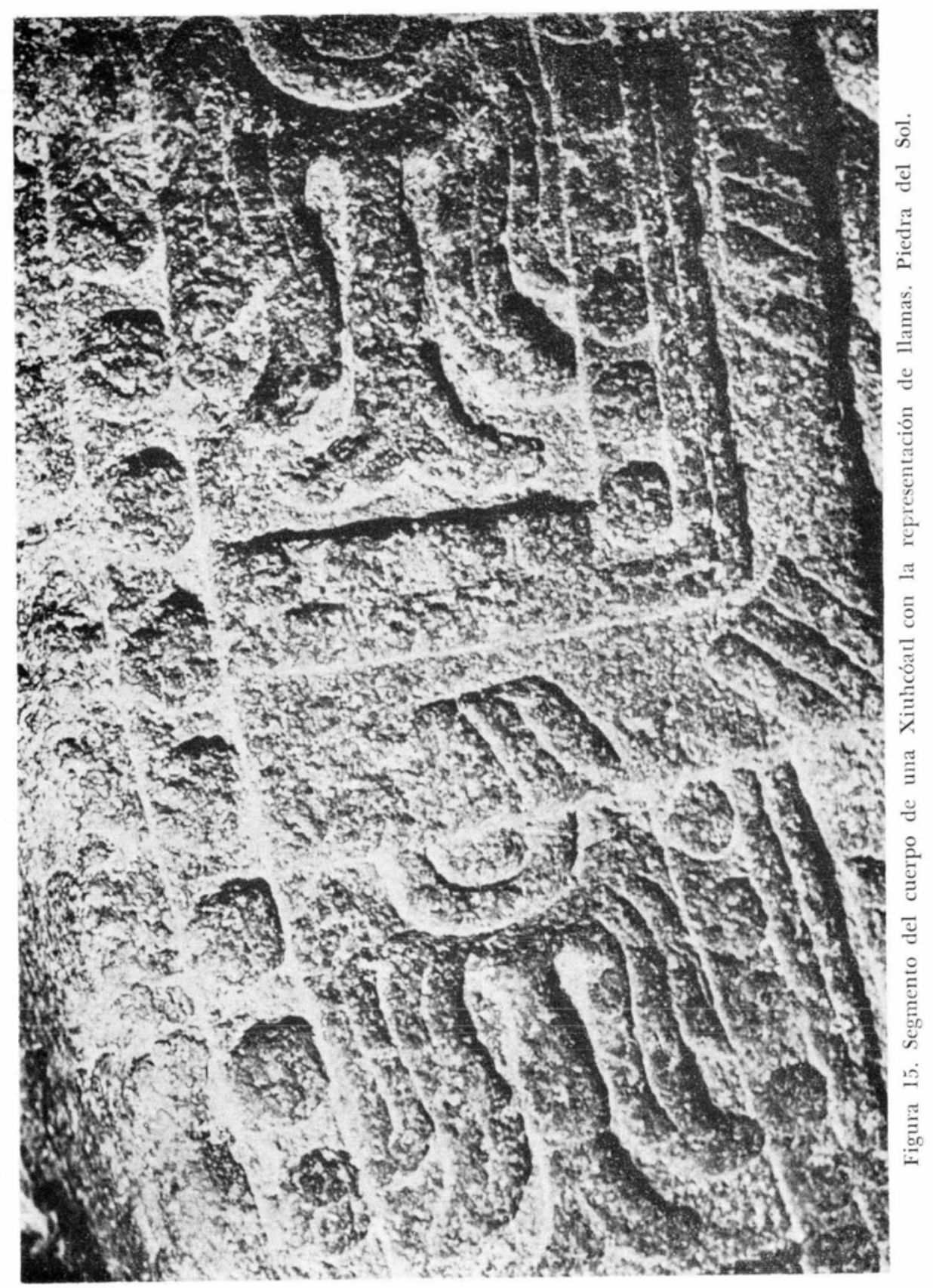


DOI: http://dx.doi.org/10.22201/iie.18703062e.1978.48.1099

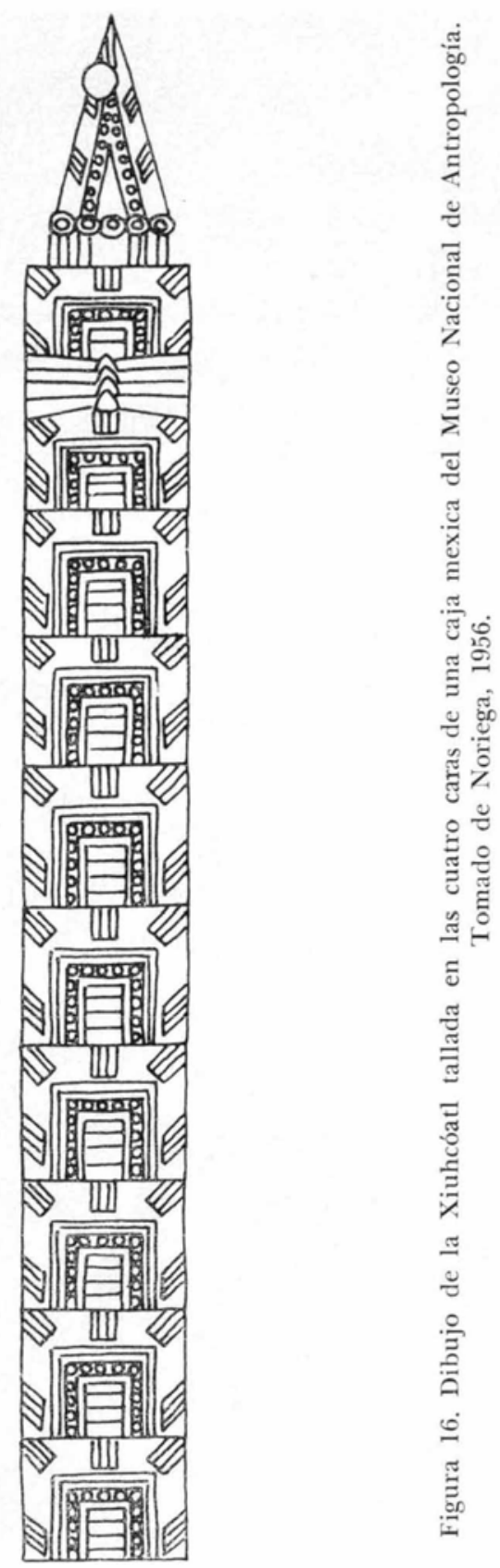


DOI: http://dx.doi.org/10.22201/iie.18703062e.1978.48.1099

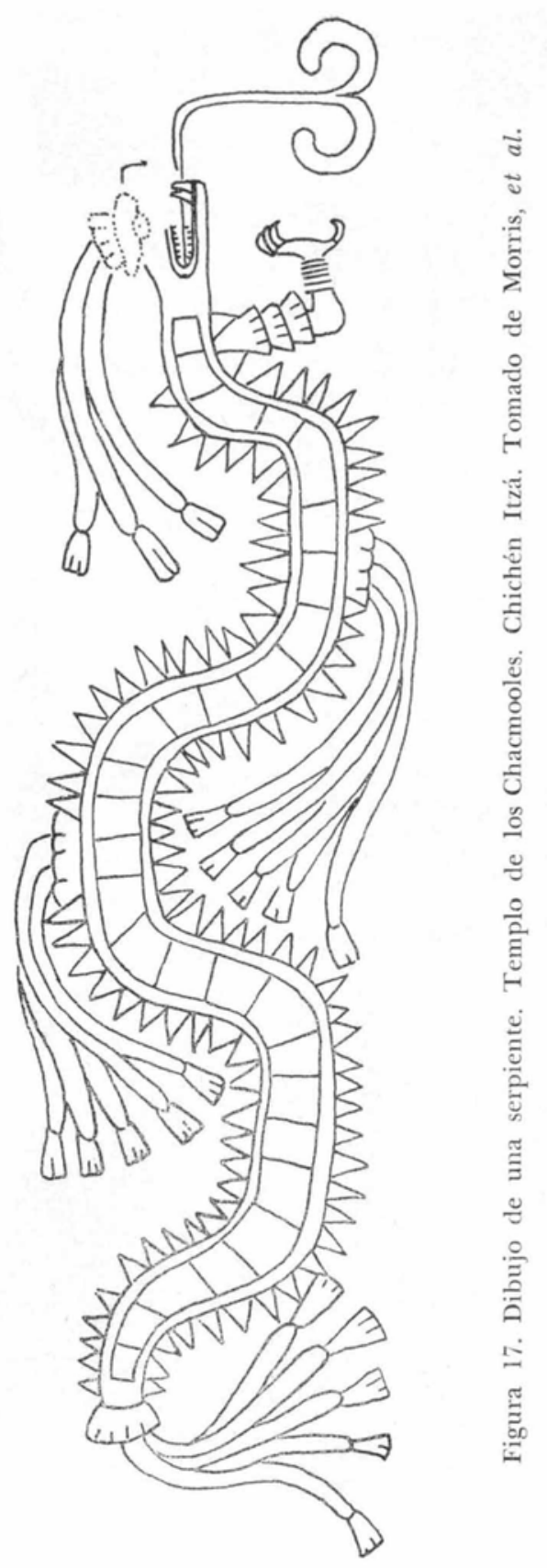




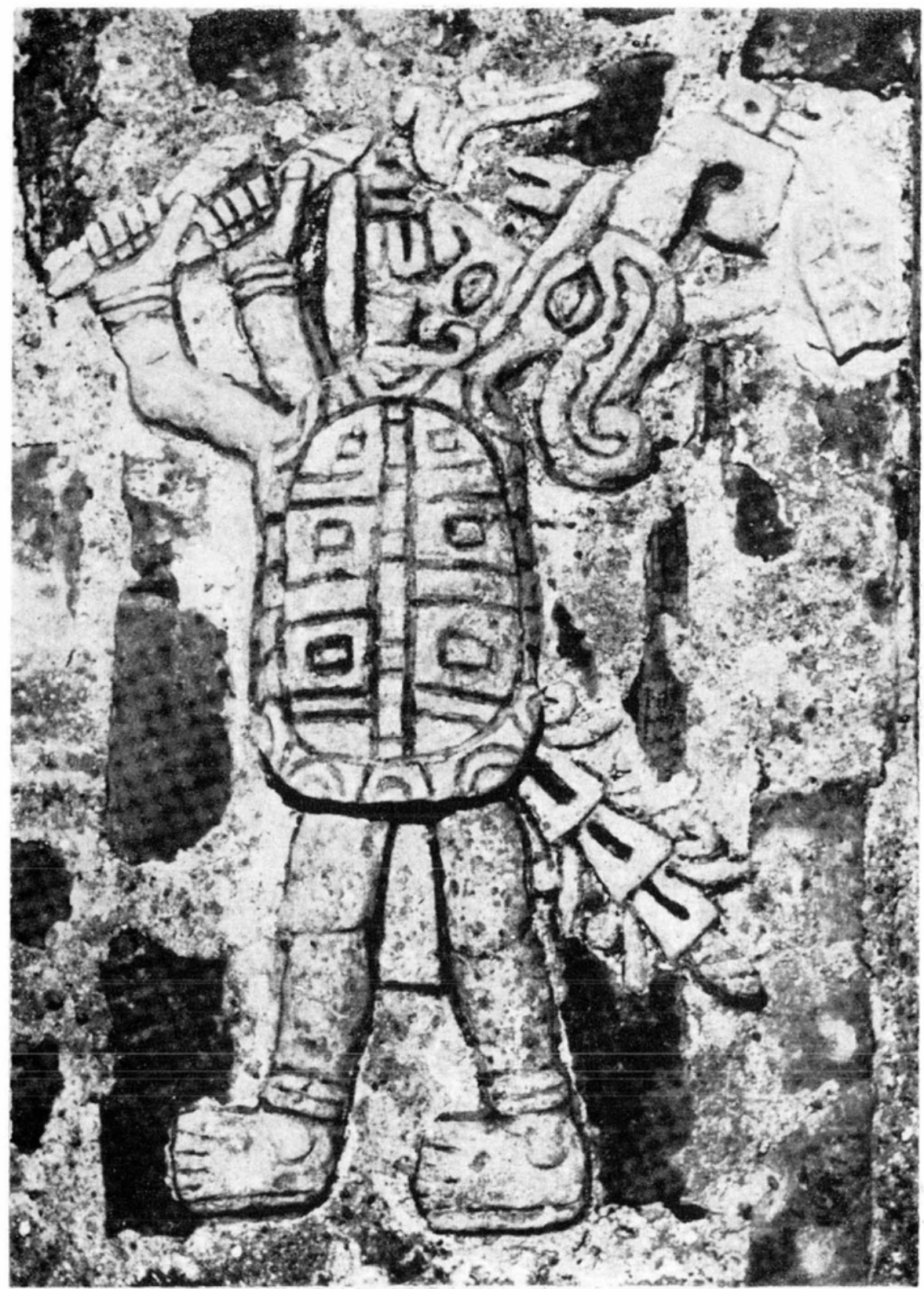

Figura 18. El 'Sacrificador Tortuga-Xiuhcóatl' de la Tumba 1 de Zaachila. 
DOI: http://dx.doi.org/10.22201/iie.18703062e.1978.48.1099



Figura 19. El Personaje Tortuga-Xiuhcóatl. Lamina 44 del Códice Nuttall. 